\title{
PRECISE PLANT HEIGHT MONITORING AND BIOMASS ESTIMATION WITH TERRESTRIAL LASER SCANNING IN PADDY RICE
}

\author{
N. Tilly a,d,*, D. Hoffmeister ${ }^{\mathrm{a}, \mathrm{d}}$, Q. Cao ${ }^{\mathrm{b}, \mathrm{d}}$, V. Lenz-Wiedemann ${ }^{\mathrm{a}, \mathrm{d}}$, Y. Miao ${ }^{\mathrm{b}, \mathrm{d}}, \mathrm{G}^{\mathrm{a}}$ Bareth $^{\mathrm{a}, \mathrm{d}}$ \\ ${ }^{a}$ Institute of Geography (GIS \& Remote Sensing Group), University of Cologne, 50923 Cologne, Germany - \\ (nora.tilly, dirk.hoffmeister, victoria.lenz, g.bareth)@uni-koeln.de \\ ${ }^{\mathrm{b}}$ Department of Plant Nutrition, China Agricultural University, 100193 Beijing, China, - \\ (qiangcao,ymiao)@cau.edu.cn \\ ${ }^{\mathrm{d}}$ International Center for Agro-Informatics and Sustainable Development (ICASD), www.icasd.org
}

KEY WORDS: Agriculture, Crop, Change Detection, Monitoring, Multitemporal, Spatial, TLS

\begin{abstract}
:
Optimizing crop management is a major topic in the field of precision agriculture as the growing world population puts pressure on the efficiency of field production. Accordingly, methods to measure plant parameters with the needed precision and within-field resolution are required. Studies show that Terrestrial Laser Scanning (TLS) is a suitable method to capture small objects like crop plants. In this contribution, the results of multi-temporal surveys on paddy rice fields with the TLS system Riegl LMS-Z420i are presented. Three campaigns were carried out during the key vegetative stage of rice plants in the growing period 2012 to monitor the plant height. The TLS-derived point clouds are interpolated to visualize plant height above ground as crop surface models (CSMs) with a high resolution of $0.01 \mathrm{~m}$. Spatio-temporal differences within the data of one campaign and between consecutive campaigns can be detected. The results were validated against manually measured plant heights with a high correlation $\left(\mathrm{R}^{2}=0.71\right)$. Furthermore, the dependence of actual biomass from plant height was evaluated. To the present, no method for the non-destructive determination of biomass is found yet. Thus, plant parameters, like the height, have to be used for biomass estimations. The good correlation $\left(\mathrm{R}^{2}=0.66\right)$ leads to the assumption that biomass can be estimated from plant height measurements. The results show that TLS can be considered as a very promising tool for precision agriculture.
\end{abstract}

\section{INTRODUCTION}

The further growing world population and increasing life expectancy but concurrently constant or even decreasing cultivation area requires agricultural field management aiming at high production and sustainability of natural resources. Due to its role as staple food, the improvement of the cultivation of rice is increasingly important, in particular for the rapidly growing Asian population. In 2011, about 650 million tonnes were produced in Asia (FAO, 2013).

In the field of precision agriculture, remote and proximal sensing methods are used for accurate crop monitoring to improve the relation between in- and outputs (Mulla, 2013). For example, rice grain yield is positively correlated to biomass and nitrogen $(\mathrm{N})$ translocation efficiency (Ntanos and Koutroubas, 2002), but over-fertilization with $\mathrm{N}$ is a major problem for soil and groundwater. Hence, precise in-season acquisition and monitoring methods are required. For monitoring the $\mathrm{N}$ status in standing crops several non-destructive methods are introduced (Yu et al., 2013; Ryu et al., 2011; Stroppiana et al., 2009; Huang et al., 2008). However, the matter of non-destructively direct biomass determination is still not solved. Thus, the biomass must be estimated based on other parameters. For paddy rice, spaceborne hyperspectral and radar data is commonly used due to the usually wide areal extent of the fields (Koppe et al., 2013; Lopez-Sanchez et al., 2010; Ribbes and Le-Toan, 1999). On field level, reflectance data measured with a hand-held radiometer is used to predict the biomass of rice plants (Gnyp et al., 2013; Casanova et al., 1998). Confalonieri et al. (2011) detected plant height as a key factor to predict rice yield potential and established a model to estimate the plant height increase, but methods for accurate in-situ measurements are rare.

Besides hyperspectral and optical sensors, the focus of research is on the use of the technology of light detection and ranging (LIDAR) for agricultural purposes. Several crops were already investigated with ground-based LIDAR approaches for various purposes like determining plant height (Zhang and Grift, 2012) and estimating biomass (Keightley and Bawden, 2010; Ehlert et al., 2009; 2008), crop density (Hosoi and Omasa, 2009; Saeys et al., 2009), or leaf area index (Gebbers et al., 2011). Furthermore, analysis of the measured intensity values can lead to the detection of single plants of maize (Höfle, 2013) or sugar beet (Hoffmeister et al., 2012). For estimating the biomass of small grain cereals like barley, oat, and wheat Lumme et al. (2008) stated Terrestrial Laser Scanning (TLS) as a promising method. Hosoi and Omasa (2012) estimated the biomass of rice based on the vertical plant area density achieved with a TLS system in combination with a mirror.

In this study, the plant height on paddy rice fields was measured with a terrestrial laser scanner to establish multi-temporal crop surface models (CSMs). As Hoffmeister et al. (2010) introduced, spatial patterns in crop growth can be detected with CSMs and the actual biomass can be estimated. Furthermore, the study presented can be used to verify the results achieved in a similar study in the preceding year (Tilly et al., 2012). All surveys are part of the activities of the International Center for Agro-Informatics and Sustainable Development (ICASD). The ICASD is an international, multidisciplinary, and cooperative

\footnotetext{
* Corresponding author: nora.tilly@uni-koeln.de
} 
research center, which was founded in 2009 by the Department of Plant Nutrition of the China Agricultural University in Beijing and the Institute of Geography at the University of Cologne, Germany (www.ICASD.org).

\section{METHODS}

\subsection{Study area}

The surveys were conducted at the Keyansuo experiment station in the city of Jiansanjiang (N 47 13'54", E 132 $\left.38^{\prime} 53^{\prime \prime}\right)$ in Heilongjiang Province in the northeast of China. Cold, dry winters and short but warm, humid summers are characteristic for the middle temperate and humid climate of the Sanjiang Plain, which is characterized by the East Asian summer monsoon (Yihui and Chan, 2005; Domrös and Gongbing, 1988). The province is an important basis for agricultural products in China (Gao and Liu, 2011).

At the Keyansuo experiment station several approaches for the management of irrigated rice fields are investigated. The focus of the field experiment examined in this contribution was on different $\mathrm{N}$ fertilizer inputs during the growing period. The amount of fertilizer was predefined for five treatments, whereas the amount for treatment six to nine was adjusted based on in-season $\mathrm{N}$ content analysis during the early and middle growing period. The field with a spatial extent of $60 \mathrm{~m}$ by $63 \mathrm{~m}$ was divided in 54 plots. One half of them were cultivated with the rice variety Kongyu 131, the other half with Longjing 21 . For both rice varieties nine treatments, which differ in the amount of applied $\mathrm{N}$ fertilizer, were repeated three times.

\subsection{Field measurements}

Three campaigns were carried out in a survey period, which captures the key vegetative stage of rice plants. Due to the stem elongation process related with the increase of tillers and plant height, remarkable differences in plant development occur during this stage. The campaigns were carried out on the $1^{\text {st }}, 9^{\text {th }}$, and $17^{\text {th }}$ of July 2012 .

For all field campaigns the terrestrial laser scanner Riegl LMS-Z420i (Riegl LMS GmbH, 2010) provided by Five Star Electronic Technologies, located in Beijing, was used. During the campaigns the instrument was fixed on a tripod, which raises the sensor $1.5 \mathrm{~m}$ above ground. In order to achieve a greater height, the tripod was erected on a small trailer behind a tractor, where it was possible. The whole study area of the experiment station was observed from nine scan positions to capture all fields and to minimize shadowing effects. For the analysis presented in this paper, four positions were of major importance, due to their position at the corners of the $\mathrm{N}$ experiment field. Two positions that were accomplished with the trailer at the south edge and two positions without the trailer at the north edge of the field.

At least four common tie points for every scan position are required to enable the merging of the point clouds in the postprocessing. To ensure the required number of tie points for each position, six high-reflective cylinders (Hoffmeister et al., 2010) were fixed on ranging poles built upon the dikes between the fields. The reflectors can be easily detected by the laser scanner. Hence, the spatial relation between all positions and the cylinders can be computed for the later referencing in the postprocessing. In the first campaign, the positions of all poles were marked in the field. By reestablishing the ranging poles for the following campaigns, all scans of each date can be merged together.

During the whole vegetation period, manual measurements were performed to monitor the development of the rice plants. Corresponding to all scan campaigns, plant heights were measured manually and destructive biomass sampling was performed.

\subsection{Postprocessing}

The first steps of the postprocessing, involving the registration of the scan positions and merging of the point clouds as well as the filtering and extraction of the area of interest (AOI) were carried out with Riegls software RiSCAN PRO, which is delivered with the laser scanner. A detailed description is given in Tilly et al. (2012). For further spatial and statistical analyses the filtered point clouds of the AOI was exported.

For the spatial analyses ArcGIS Desktop 10 by Esri was used. The point clouds were interpolated with the Inverse Distance Weighing (IDW) algorithm to receive a raster for each plot with

\section{Multi-temporal Crop Surface Models}

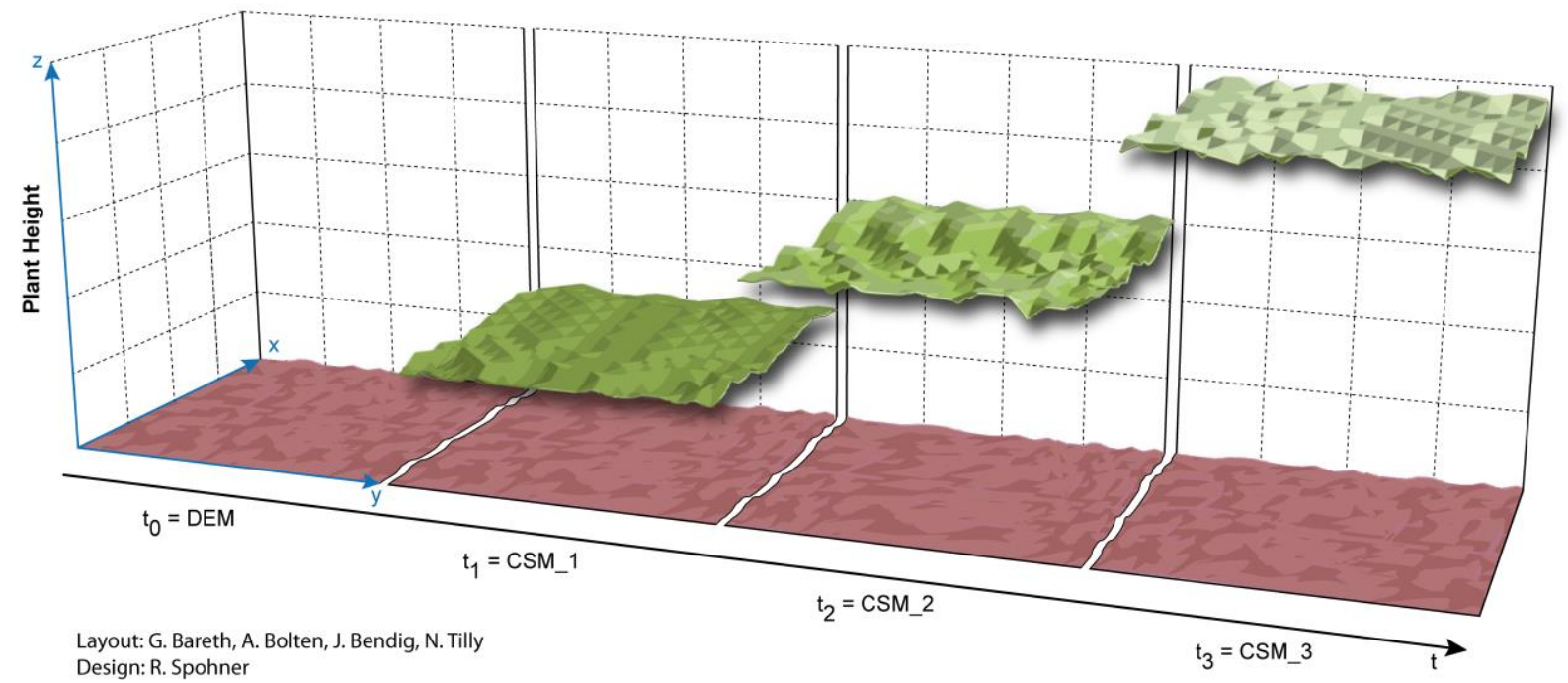

Figure 1. General concept for the construction of multi-temporal crop surface models (CSMs). 
a consistent spatial resolution of $1 \mathrm{~cm}$ representing a Digital Surface Model (DSM). For the calculation of the plant heights, a common reference surface is required. Points on the ground in the point clouds from the first campaign were used to interpolate a Digital Elevation Model (DEM), which is used as reference surface. Following, a crop surface model (CSM) was generated for each plot of all campaigns. Therefore, the DEM is subtracted from the respective DSM (Figure 1). The result is a CSM for each plot with a high spatial resolution representing plant height above ground for the specific time step in the growing period. By subtracting consecutive CSMs, the plant growth between the dates can be spatially measured.

The manually measured plant heights were used to validate the TLS-derived results. For the statistical analyses, the plant heights of both measurement methods were averaged for each plot. Each CSM of a plot was previously clipped with an inner buffer of $60 \mathrm{~cm}$ to prevent border effects.

As mentioned above, the non-destructively direct estimation of crop biomass on field level is not solved yet, but indirect approaches successfully used plant height as predictor. In order to investigate the correlation between plant height and biomass of rice plants, destructive biomass sampling was performed for all repetitions of the five treatments with predefined amount of fertilizer for both varieties $(n=30)$.

\section{RESULTS}

\subsection{Spatial analysis}

The TLS-derived CSMs are visualized as maps of height. Figure 2 shows the maps for four selected plots of the first $\mathrm{N}$ fertilizer treatment. On the left side, two repetition plots of Kongyu 131 and on the right side two repetition plots of Longjing 21 are shown. Each raster data set has a resolution of $0.01 \mathrm{~m}$. For all plots the variability in plant height within the plot is observable. In the first repetition of Kongyu 131, the linear structure of the rice plant rows within the plots is detectable. Further, it can be seen that the plant height of Longjing 21 is higher than Kongyu 131, particularly at the last date. Further, the temporal development of spatial patterns can be monitored. In the first repetition of Longjing 21 lower plant height values occur in the north, east, and south corners of the CSM from the first campaign. Whereas those patterns are not detectable in the north and east corners of the CSMs from both later campaigns, lower plant height values remain in the south corner.

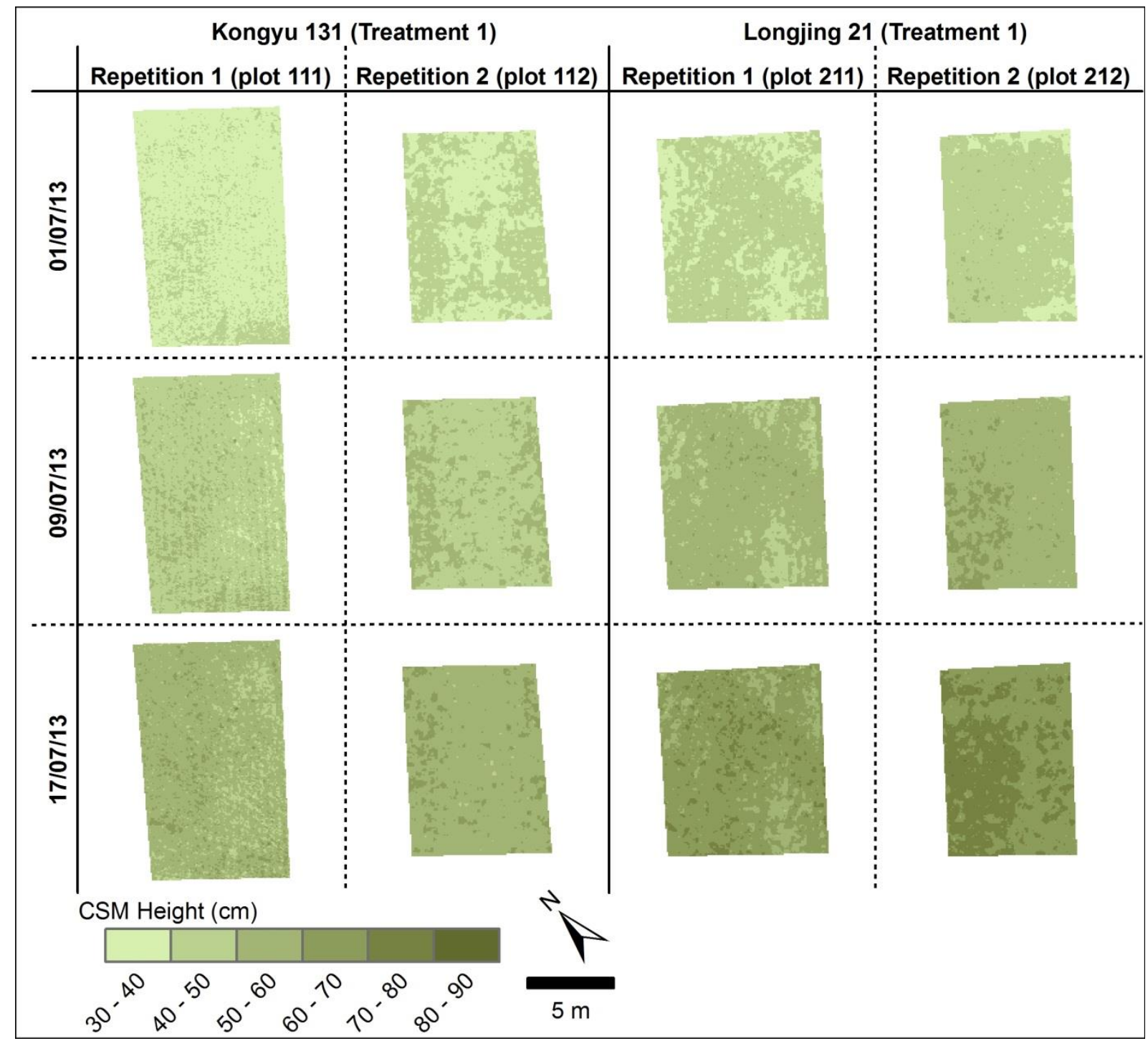

Figure 2. Crop surface models (CSM) visualised as maps of height for four selected plots on each campaign date (Plots are marked in Figure 3). 
Table 1. Mean CSM-derived and manually measured plant heights.

\begin{tabular}{|c|c|c|c|c|c|c|c|c|c|}
\hline & \multirow[b]{2}{*}{$\mathbf{n}$} & \multicolumn{4}{|c|}{ Plant height from CSM $(\mathrm{cm})$} & \multicolumn{4}{|c|}{ Measured plant height $(\mathrm{cm})$} \\
\hline & & $\mu$ & $\sigma$ & Min & $\operatorname{Max}$ & $\mu$ & $\sigma$ & Min & Max \\
\hline \multicolumn{10}{|l|}{$01 / 07 / 2013$} \\
\hline Kongyu 131 & 27 & 45.62 & 3.56 & 37.80 & 53.25 & 41.78 & 3.24 & 36.00 & 49.50 \\
\hline Longjing 21 & 27 & 43.74 & 2.26 & 39.50 & 48.82 & 46.07 & 4.41 & 35.50 & 54.50 \\
\hline \multicolumn{10}{|l|}{$01 / 07 / 2013$} \\
\hline Kongyu 131 & 27 & 55.73 & 4.35 & 46.66 & 64.64 & 48.41 & 4.02 & 40.50 & 55.00 \\
\hline Longjing 21 & 27 & 58.06 & 2.90 & 51.93 & 63.44 & 52.28 & 4.98 & 42.50 & 61.00 \\
\hline \multicolumn{10}{|l|}{$09 / 07 / 2013$} \\
\hline Kongyu 131 & 27 & 65.09 & 5.67 & 54.62 & 76.46 & 63.22 & 4.93 & 53.00 & 72.00 \\
\hline Longjing 21 & 27 & 68.98 & 4.01 & 60.25 & 75.24 & 69.30 & 3.73 & 59.50 & 75.50 \\
\hline
\end{tabular}

\subsection{Statistical analysis}

The mean plant height was calculated for each plot and campaign date for both measurement methods to execute correlation and regression analyses. Common values are shown in Table 1. Except the mean CSM heights from the first campaign, the values for Longjing 21 are always higher than for Kongyu 131. Apart from the values for Kongyu 131 of the last campaign, the standard deviation for each campaign is less than $5 \mathrm{~cm}$. Regarding the two measurement methods the differences between the related mean values are for both varieties for the first and third campaign less than $\sim 3 \mathrm{~cm}$. The differences for the second campaign are higher $(\sim 7 \mathrm{~cm})$. In addition, the related values from both measurement methods and the resulting regression line are shown in Figure 4. The linear correlation with a high correlation coefficient $\left(\mathrm{R}^{2}=0.71\right)$ is clearly observable.

The differences between the mean plant height values from both measurement methods can also be visualized for each plot. Figure 3 shows the difference between the mean heights from the CSMs and the manually measured plant heights for the third campaign. For about half of the plots the difference is less than $2 \mathrm{~cm}$, further $30 \%$ differ between 2 and $5 \mathrm{~cm}$ and only $20 \%$ show a higher error, reaching the maximum at $\sim 10 \mathrm{~cm}$.

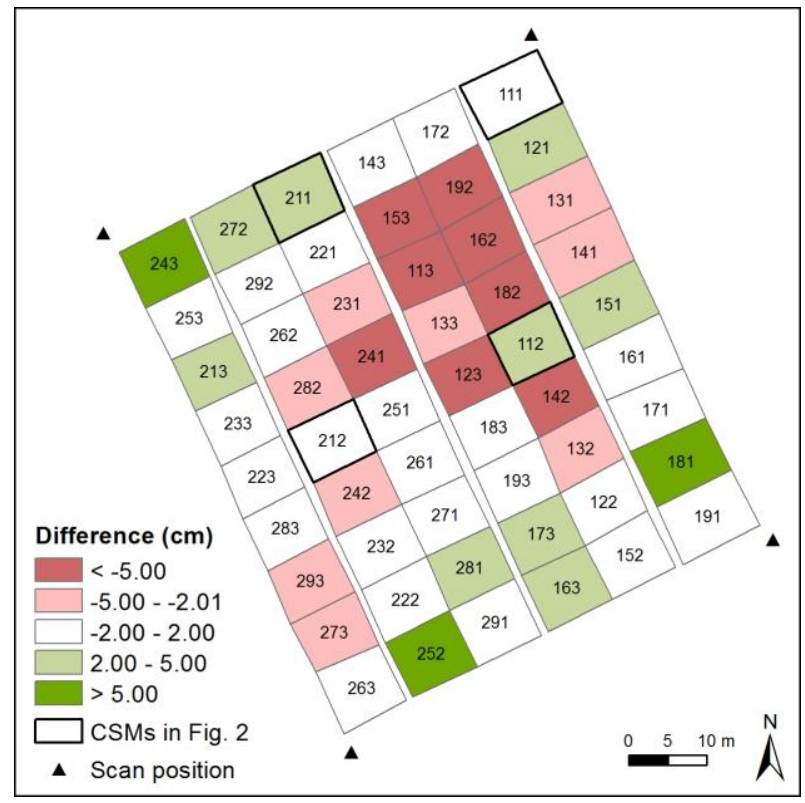

Figure 3. Difference between the mean CSM-derived and manually measured plant heights for the third campaign.

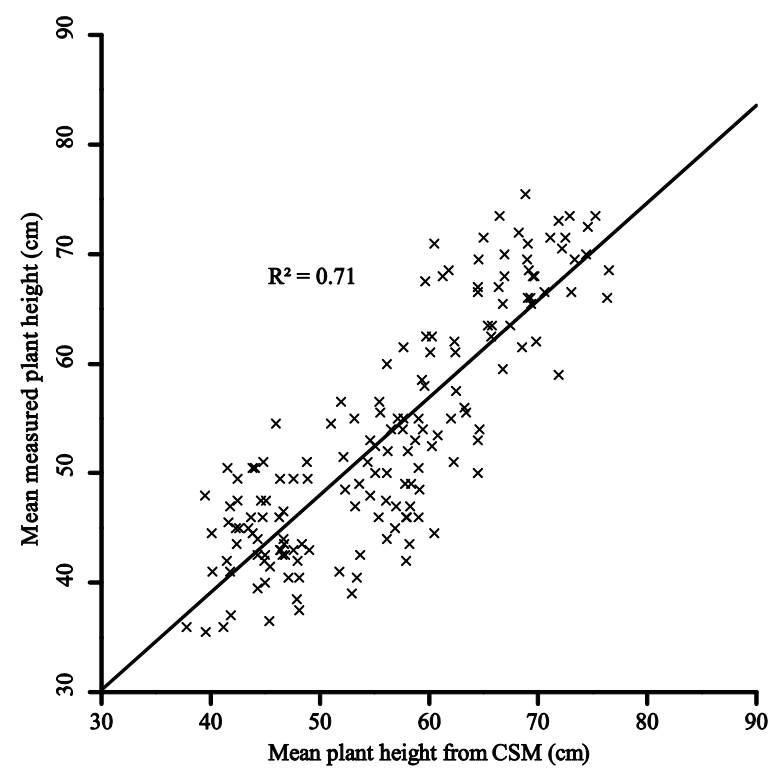

Figure 4. Regression of the mean CSM-derived and manually measured plant heights $(n=162)$.

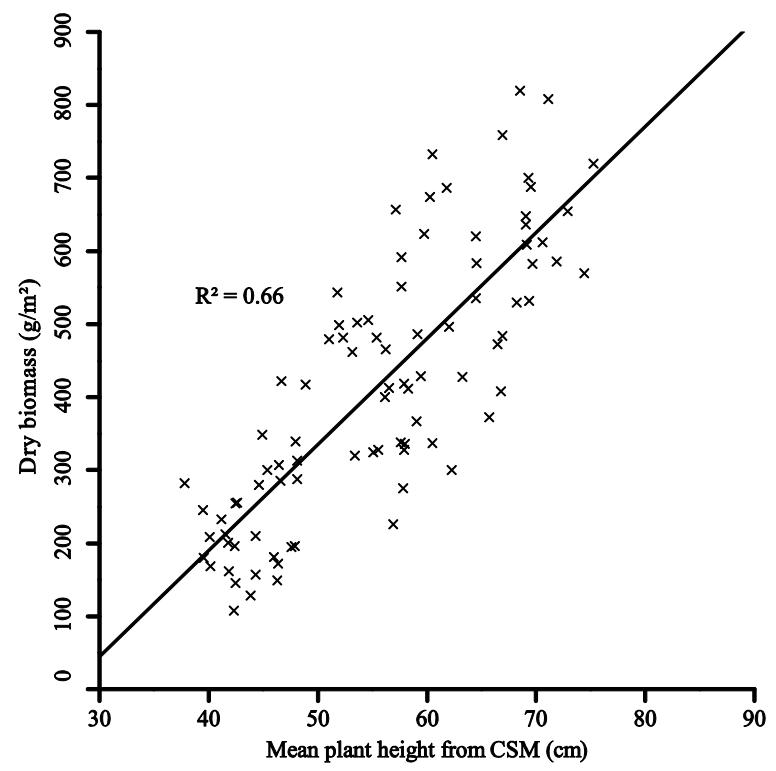

Figure 5. Regression of the mean CSM-derived plant height and the dry biomass for treatment one to five $(\mathrm{n}=90)$. 
Furthermore, statistical analyses were performed to examine the dependence of the actual biomass from the plant height. As it can be seen in Figure 5 a good correlation between plant height and dry biomass was achieved $\left(\mathrm{R}^{2}=0.66\right)$ and the linear regression shows the dependence of biomass from plant height.

\section{DISCUSSION}

Generally, the data acquisition with the laser scanner in the field worked very well. Earlier studies with a comparable set-up (Tilly et al., 2012; Hoffmeister et al., 2010) show the usability of this approach, but further improvement is still desirable. For example, problems with the transportation of the scanner on the small dikes between the plots have to be solved. Furthermore, the linear structure of the rice plant rows can be better observed in plots close to the scan positions (cf. plot 111 in Figure 2). Therefore, recent developments in Mobil Laser Scanning (MLS) have to be considered. The Akhka MLS system (Kukko et al., 2012), where a laser scanner is attached to a backpack might be useful to reach areas with limited access and to achieve a regular covering. However, the presumably lower accuracy must be regarded. Compared to TLS measurements, the system has an absolute accuracy level of $20 \mathrm{~mm}$ (Kukko et al., 2012).

A major advantage of the terrestrial laser scanner for agriculture is that a fast and easily achievable acquisition of the whole field is possible. However, some problems that are always related to TLS in agricultural applications, like noise in the point clouds occur (Ehlert et al., 2009; Lumme et al., 2008). They can be caused by wind, rain, insects, or small particles in the air, reflections on water, and other effects. In this study, such points were removed manually.

Beside the well working acquisition in the field, the results show the applicability of TLS to achieve CSMs with a high spatial resolution of up to $1 \mathrm{~cm}$. As mentioned, commonly spaceborne data with a resolution not higher than $1 \mathrm{~m}$ is used for the mapping of paddy rice fields (Koppe et al., 2013; Lopez-Sanchez et al., 2010; Ribbes and Le-Toan, 1999). Reconsidering the model from Confalonieri et al. (2011) the CSM-derived plant height can be used to predict yield potential for rice.

Due to the high precision and resolution of the CSMs, border effects, resulting in differences between internal and external rice plants in a plot (Wang et al., 2013) must be taken into account. In this study, a buffer was applied to cut off the outmost rows. Hence, such effects had no influence on the mean value calculation. But as border effects are a general problem for the estimation of rice yield, the high resolution of the TLS-derived CSMs might be useful to quantify differences between internal and external rows.

Furthermore, the high correlation $\left(\mathrm{R}^{2}=0.71\right)$ as well as the small differences between the mean CSM-derived and manually measured plant heights (cf. Figure 3) show the usability of the presented approach to monitor plant height in paddy rice. As mentioned, to this day, it is impossible to directly measure crop biomass non-destructively. The good correlation $\left(\mathrm{R}^{2}=0.66\right)$ between plant height and dry biomass confirms the applicability of plant height as a predictor for estimating the actual biomass. The data presented in this contribution confirms the results of the preceding year (Tilly et al., 2012) where similar correlations were reached. In contrast, Hosoi and Omasa (2012) achieved good results for estimating biomass of rice plants based on the vertical plant area density measured with a portable scanner in combination with a mirror. However, this set-up might be less practical for the application on larger scale fields.

\section{CONCLUSION AND OUTLOOK}

In summary, the presented method to derive CSMs with TLS is well suitable for the non-destructive monitoring of rice plant height and estimating biomass. The very high spatial resolution and accuracy of the point clouds are the most outstanding features of TLS. Regarding the investigated field experiment, further studies might focus on the differences between the two rice varieties and the different fertiliser treatments. Furthermore, the transferability to larger fields should be investigated.

As mentioned, the transportation of the scanner on the field caused some problems. One solution might be a lightweight mobile system like the Akhka MLS system (Kukko et al., 2012) or the use of Unmanned Aerial Vehicles (UAV). Bendig et al. (2013) successfully used UAV-based imaging to generate CSMs. A promising device for attaching a laser scanner to a UAV is for example the Riegl LMS-Q160, as Bareth et al. (2011) proposed.

\section{ACKNOWLEDGEMENTS}

This work was financially supported by the International Bureau of the German Federal Ministry of Education and Research (BMBF, project number 01DO12013) and the German Research Foundation (DFG, project number BA 2062/8-1). We gratefully thank the Qixing Research and Development Centre, the Jiansanjiang Agricultural Research Station (both located in Heilongjiang Province, China) and Five Star Electronic Technologies (Beijing, China) for good cooperation. Furthermore, we like to thank RIEGL LMS GmbH (Horn, Austria) for continuous support.

\section{REFERENCES}

Bareth, G., Bolten, A. and Bendig, J., 2011. Potentials of lowcost mini-UAVs. In: Lenz-Wiedemann, V. and Bareth, G. (eds). Proc. of the Workshop on Remote Sensing Methods for Change Detection and Process Modelling, Cologne, Germany. Kölner Geographische Arbeiten, 192, pp. 1-8.

Bendig, J., Bolten, A. and Bareth, G., 2013 (accepted). UAVbased imaging for multi-temporal, very high resolution crop surface models (CSMs) to monitor crop growth variability. Photogrammetrie, Fernerkundung, Geoinformation, 12p.

Casanova, D., Epema, G.F. and Goudriaan, J., 1998. Monitoring rice reflectance at field level for estimating biomass and LAI. Field Crops Research, 55, pp. 83-92.

Confalonieri, R., Bregaglio, S., Rosenmund, A.S., Acutis, M. and Savin, I., 2011. A model for simulating the height of rice plants. European Journal of Agronomy, 34, pp. 20-25.

Domrös, M. and Gongbing, P., 1988. The Climate of China. Springer Verlag, Berlin.

Ehlert, D., Adamek, R. and Horn, H-J., 2009. Laser rangefinder-based measuring of crop biomass under field conditions. Precision Agriculture, 10 (5), pp. 395-408. doi: 10.1007/s11119-009-9114-4.

Ehlert, D., Horn, H-J. and Adamek, R., 2008. Measuring crop biomass density by laser triangulation. Computers and 
Electronics in Agriculture, 61, pp. 117-125. doi: 10.1016/j.compag.2007.09.013.

FAO (Food and Agriculture Organization) 2013. http://faostat.fao.org/ (Accessed 27 March 2013)

Gao, J. and Liu, Y., 2011. Climate warming and land use change in Heilongjiang Province, Northeast China. Applied Geography, 31, pp. 476-482.

Gebbers, R., Ehlert, D. and Adamek, R., 2011. Rapid Mapping of the Leaf Area Index in Agricultural Crops. Agronomy Journal, 103 (5), pp. 1532-1541.

Gnyp, M.L., Yu, K., Aasen, H., Yao, Y., Huang, S., Miao, Y. and Bareth, G., 2013. Analysis of crop reflectance for estimating biomass in rice canopy at different phenological stages. Photogrammetrie, Fernerkundung, Geoinformation, 4/2013, pp. 267-281.

Hoffmeister, D., Bolten, A., Curdt, C., Waldhoff, G. and Bareth, G., 2010. High resolution Crop Surface Models (CSM) and Crop Volume Models (CVM) on field level by terrestrial laserscanning. Proc. SPIE, 7840, 78400E, 6 p. doi: 10.1117/12.872315.

Hoffmeister, D., Tilly, N., Bendig, J. Curdt, C. and Bareth, G., 2012. Detektion von Wachstumsvariabilität in vier Zuckerrübensorten durch multi-temporales terrestrisches Laserscanning. In: Clasen, M., Fröhlich, G., Bernhardt, H., Hildebrand, K., Theuvsen, B. (Eds.). Informationstechnologie für eine nachhaltige Landbewirtschaftung, Proc. 32. GILJahrestagung, Freising, 29 Februar - 1 März, pp. 135-138.

Höfle, B., 2013 (in press). Radiometric Correction of Terrestrial LiDAR Point Cloud Data for Individual Maize Plant Detection. IEEE Geoscience and Remote Sensing Letters, 5 p. doi: 10.1109/LGRS.2013.2247022.

Hosoi, F. and Omasa, K., 2009. Estimating vertical plant area density profile and growth parameters of a wheat canopy at different growth stages using three-dimensional portable lidar imaging. ISPRS Journal of Photogrammetry and Remote Sensing, 64, pp. 151-158.

Hosoi, F. and Omasa, K., 2012. Estimation of vertical plant area density profiles in a rice canopy at different growth stages by high-resolution portable scanning lidar with a lightweight mirror. ISPRS Journal of Photogrammetry and Remote Sensing, 74, pp. 11-19.

Huang, J., He, F., Cui, K., Buresh, R.J., Xu, B., Gong, W. and Peng, S., 2008. Determination of optimal nitrogen rate for rice varieties using a chlorophyll meter. Field Crops Research, 105 (1-2), pp. 70-80.

Keightley, K.E. and Bawden, G.W., 2010. 3D volumetric modeling of grapevine biomass using Tripod LiDAR. Computers and Electronics in Agriculture, 74, pp. 305-312.

Koppe, W., Gnyp, M., Hütt, C., Yao, Y., Miao, Y., Chen, X. and Bareth, G., 2013. Rice monitoring with multi-temporal and dual-polarimetric TerraSAR-X data. International Journal of Applied Earth Observation and Geoinformation, 21, pp. 568576.

Kukko, A. Kaartinen, H., Hyyppä, J. and Chen, Y., 2012. Multiplatform Mobile Laser Scanning: Usability and Performance. Sensors, 12, pp. 11712-11733.
Lopez-Sanchez, J.M., Ballester-Berman, J.D. and Hainsek, I., 2010. First results of rice monitoring practices in Spain by means of time series of TerraSAR-X dualpol images. IEEE Journal of Selected Topics in Applied Earth Observations and Remote Sensing, 4 (2), pp. 412-422.

Lumme, J., Karjalainen, M., Kaartinen, H., Kukko, A., Hyyppä, J., Hyyppä, H., Jaakkola, A. and Kleemola, J., 2008. Terrestrial Laser Scanning of agricultural crops. In: The International Archives of Photogrammetry, Remote Sensing and Spatial Information Sciences, Beijing, China, Vol. XXXVII, Part B5, pp. 563-566.

Mulla, D.J., 2013. Twenty five years of remote sensing in precision agriculture: Key advances and remaining knowledge gaps. Biosystems Engineering, 114, pp. 358-371.

Ntanos, D.A. and Koutroubas, S.D., 2002. Dry matter and $\mathrm{N}$ accumulation and translocation for Indica and Japonica rice under Mediterranean conditions. Field Crops Research, 74, pp. 93-101.

Ribbes, F. and Le-Toan, T., 1999. Rice field mapping and monitoring with RADARSAT data. International Journal of Remote Sensing, 20 (4), pp. 745-765.

Riegl LMS GmbH, 2010. Datasheet Riegl LMS-Z420i. http://www.riegl.com/uploads/tx_pxpriegldownloads/10_DataS heet_Z420i_03-05-2010.pdf (7. Jun 3013)

Ryu, C., Suguri, M. and Umeda, M., 2011. Multivariate analysis of nitrogen content for rice at the heading stage using reflectance of airborne hyperspectral remote sensing. Field Crops Research, 122, pp. 214-224.

Saeys, W., Lenaerts, B., Craessaerts, G. and De Baerdemaeker, J., 2009. Estimation of the crop density of small grains using LiDAR sensors. Biosystems Engineering, 102, pp. 22-30.

Stroppiana, D., Boschetti, M., Brivio, P.A. and Bocchi, S., 2009. Plant nitrogen concentration in paddy rice from field canopy hyperspectral radiometry. Field Crops Research, 111, pp. 119-129.

Tilly, N., Hoffmeister, D., Liang, H., Cao, Q., LenzWiedemann, V., Miao, Y. and Bareth, G., 2012. Evaluation of terrestrial laser scanning for rice growth monitoring. In: The International Archives of the Photogrammetry, Remote Sensing and Spatial Information Sciences, Melbourne, Australia, Vol. XXXIX, Part B7, pp. 351-356.

Wang, K., Zhou, H., Wang, B., Jian, Z., Wang, F., Huang, J., Nie, L., Cui, K. and Peng, S., 2013. Quantification of border effect on grain yield measurement of hybrid rice. Field Crops Research, 141, pp. 47-54.

Yihui, D. and Chan, J.C.L., 2005. The East Asian summer monsoon: an overview. Meteorology and Atmospheric Physics, 89, pp. 117-142.

Yu, K., Li, F., Gnyp, M.L., Miao, Y., Bareth, G. and Chen, X., 2013. Remotely detecting canopy nitrogen concentration and uptake of paddy rice in the Northeast China Plain. ISPRS Journal of Photogrammetry and Remote Sensing, 78, pp. 102115.

Zhang, L. and Grift, T.E., 2012. A LIDAR-based crop height measurement system for Miscanthus giganteus. Computers and Electronics in Agriculture, 85, pp. 70-76. 